\title{
Clinical utility gene card for: Menkes disease
}

\author{
Zeynep Tümer ${ }^{\star, 1}$ and Leo Klomp ${ }^{2}$ \\ European Journal of Human Genetics (2011) 19, doi:10.1038/ejhg.2011.56; published online 13 April 2011
}

\section{DISEASE CHARACTERISTICS}

1.1 Name of the disease (synonyms)

Menkes disease (MD).

Occipital horn syndrome (OHS), milder allelic form of MD.

1.2 OMIM\# of the disease

309400, 304150.

1.3 Name of the analysed genes or DNA/chromosome segments ATP7A.

\subsection{OMIM\# of the gene(s)}

300011.

\subsection{Mutational spectrum}

$\mathrm{MD}$ is inherited as an $\mathrm{X}$-linked recessive trait and, as expected, the vast majority of patients are males. To date, $\sim 210$ different mutations (from chromosome aberrations to large deletions or duplications, and single-amino-acid substitutions) affecting ATP7A have been reported. ${ }^{1-9}$ Chromosome abnormalities affecting ATP7A were detected in eight patients, one male ${ }^{7}$ and seven female patients. One of the female patients was mosaic for the Turner karyotype and the rest had X;autosome translocations (reviewed in Sirleto et al. ${ }^{8}$ ). Approximately one-third of the ATP7A mutations are gross deletions ranging in size from a single exon to deletion of the whole gene except for the first two exons, ${ }^{6,9}$ and four patients have partial gene duplications. ${ }^{9}$ The rest comprise $\sim 140$ different intragenic mutations: missense $(34 \%)$, nonsense $(17 \%)$ and splice-site mutations $(17 \%)$, and deletions/insertions/duplications $(32 \%){ }^{1-5,9}$ There is no obvious correlation between the mutations and the clinical course of MD. However, in general, patients with a milder phenotype (such as OHS) have a higher proportion of mutations, which lead to a partially functional protein or result in reduced amounts of an otherwise normal protein. ${ }^{10}$ Recently, missense ATP7A mutations have been reported in two families with late-onset X-linked hereditary distal motor neuropathy without signs of copper deficiency. ${ }^{11}$

\subsection{Analytical methods}

Initial diagnosis of MD is suggested by clinical features (especially typical hair changes), and supported by demonstration of reduced levels of serum copper and ceruloplasmin. ${ }^{10}$ However, in the neonatal period these markers should be interpreted with caution, as their levels are low in healthy newborns also. ${ }^{10}$ In this period, plasma catecholamine analysis (ratio of DOPA to dihydroxyphenylglycol) indicative of dopamine $\beta$-hydroxylase deficiency may be used as a rapid diagnostic test, but this test does not provide definitive evidence for MD. ${ }^{10}$

A biochemical test for MD exists and is based on intracellular accumulation of copper due to impaired efflux. Accumulation is evaluated in cultured cells, mainly fibroblasts, by measuring radioactive copper $\left({ }^{64} \mathrm{Cu}\right)$ retention after a 20 -h pulse, and impaired efflux is directly determined after a $24-\mathrm{h}$ pulse-chase period. However, these analyses demand specialised expertise and are performed only in a few centres around the world. ${ }^{9}$

The ultimate diagnostic proof of MD is the demonstration of the molecular defect in ATP7A, which is located on chromosome Xq13.3. The 8.5-kb transcribed sequence of ATP7A is organised in 23 exons, in which the ATG start codon is in exon 2 and the last exon includes the TGA stop codon and a large $3^{\prime}$ untranslated region (UTR). ${ }^{9}$

As exon deletions account for about one-third of ATP7A mutations, multiplex ligation-dependent probe amplification (MLPA) can be carried out as the first DNA test.

Small intragenic mutations of ATP7A are examined by PCR amplification and sequencing of all the coding exons using genomic DNA. In affected males, deletions can also be detected by genomic sequencing.

Even though, in general, males are affected and heterozygous females are non-symptomatic carriers, owing to skewed X-chromosome inactivation, few affected females with chromosome aberrations, mainly translocations, have been reported. In case of a symptomatic female patient, chromosome analysis is the first test to be carried out. In heterozygote females, $\mathrm{X}$-chromosome inactivation assay can be carried out to assess for unfavourable skewing.

\subsection{Analytical validation}

General quality control criteria for molecular genetic testing apply. Confirmation of mutation in an independent biological sample of the affected case is the most ideal way. However, this is not always a possibility.

\section{Validation of sequence analysis results}

Sequencing is always carried out using both sense and anti-sense primers and mutation should be present in both directions. When a mutation is detected, a new PCR is carried out and the product is sequenced with both primers.

\section{Validation of MLPA results}

When two consecutive exons are deleted (as detected by two different MLPA probes), this is an internal validation. Cases in which a single exon deletion is found, this should be validated with another method such as quantitative PCR.

${ }^{1}$ Center for Applied Human Molecular Genetics, Kennedy Center, Glostrup, Denmark; ${ }^{2}$ Department of Metabolic and Endocrine Diseases, UMC Utrecht, Utrecht, The Netherlands ${ }^{*}$ Correspondence: Professor Z Tümer, Center for Applied Human Molecular Genetics, Kennedy Center, Gl. Landevej 7, Glostrup 2600, Denmark. Tel: +45 4326 1055;

Fax: +45 4343 1130; E-mail: zet@kennedy.dk 
1.8 Estimated frequency of the disease (incidence at birth ('birth prevalence') or population prevalence) The incidence of MD is calculated as 1 in 300000 in five European countries and as 1 in 360000 in Japan. ${ }^{9}$ In Australia, the incidence is reported to be much higher ( 1 in 50000-100 000), but this might be due to a founder effect. ${ }^{9}$

1.9 If applicable, prevalence in the ethnic group of investigated person

Not applicable.

\subsection{Diagnostic setting}

\begin{tabular}{lll}
\hline & Yes & No \\
\hline A. (Differential) diagnostics & $\bigotimes$ & $\square$ \\
B. Predictive testing & $\bigotimes$ & $\square$ \\
C. Risk assessment in relatives & $\bigotimes$ & $\square$ \\
D. Prenatal & $\bigotimes$ & $\square$ \\
\hline
\end{tabular}

Comment:

Ultimate diagnostic proof of MD is the demonstration of the molecular defect in ATP7A. However, because of the large size of the gene and the variety of the mutations observed in different families, detection of the genetic defect in a given family may take time. Therefore, in at-risk families, it is very important to define the ATP7A mutation of the family in due time and identify the heterozygote females before an eventual pregnancy and prenatal diagnosis.

\section{TEST CHARACTERISTICS}

\begin{tabular}{|c|c|c|c|c|}
\hline & \multicolumn{2}{|c|}{ Genotype or disease } & \multirow{2}{*}{$\begin{array}{l}\text { A: True positives } \\
\text { B: False positives }\end{array}$} & \multirow{2}{*}{$\begin{array}{l}\text { C: False negative } \\
\text { D: True negative }\end{array}$} \\
\hline & Present & Absent & & \\
\hline \multicolumn{5}{|l|}{ Test } \\
\hline Positive & A & B & $\begin{array}{l}\text { Sensitivity: } \\
\text { Specificity: }\end{array}$ & $\begin{array}{l}A /(A+C) \\
D /(D+B)\end{array}$ \\
\hline Negative & C & D & $\begin{array}{l}\text { Positive predictive value: } \\
\text { Negative predictive value: }\end{array}$ & $\begin{array}{l}A /(A+B) \\
D /(C+D)\end{array}$ \\
\hline
\end{tabular}

\subsection{Analytical sensitivity}

(proportion of positive tests if the genotype is present)

Almost $100 \%$ with DNA methods. In routine analysis, only the mutations within the coding exons and flanking intron sequences are screened in patients. Theoretically, some mutations can be within the $5^{\prime}$ - or $3^{\prime}$ UTRs of the gene, but these regions are not investigated in routine because of the large size of these regions $(3.8 \mathrm{~kb})$ and because of the fact that the mutations within these regions have not been reported.

\subsection{Analytical specificity}

(proportion of negative tests if the genotype is not present)

$100 \%$ with DNA methods.

\subsection{Clinical sensitivity}

(proportion of positive tests if the disease is present)

The clinical sensitivity can be dependent on variable factors such as age or family history. In such cases, a general statement should be given, even if a quantification can only be made case by case.
95-100\%. In some cases, mutations cannot be identified in the protein-coding region of ATP7A. This can either be due to existence of a mutation somewhere else, affecting the gene regulation, or due to presence of a yet unknown gene, leading to a similar phenotype as MD.

\subsection{Clinical specificity}

(proportion of negative tests if the disease is not present)

The clinical specificity can be dependent on variable factors such as age or family history. In such cases, a general statement should be given, even if a quantification can only be made case by case.

Almost 100\%.

\subsection{Positive clinical predictive value} (life-time risk to develop the disease if the test is positive) $100 \% . \mathrm{MD}$ is an X-linked recessive disorder and ATP7A mutations are fully penetrant in males. The diagnosis is usually suspected by the age of 3-6 months and the severely affected patients die usually before the third year of life. Patients affected with OHS have later-onset disease and progress more slowly.

\subsection{Negative clinical predictive value} (probability of not to develop the disease if the test is negative) Assume an increased risk based on family history for a non-affected person. Allelic and locus heterogeneity may need to be considered.

Index case in that family had been tested:

$100 \%$ if the individual is examined for the mutation found in the index patient. MD is not a late-onset disorder. The diagnosis is usually suspected by the age of 3-6 months and the severely affected patients die usually before the third year of life.

Index case in that family had not been tested:

Almost $100 \%$. In rare MD cases, the underlying genetic defect may not be identified. $\mathrm{MD}$ is not a late-onset disorder and the diagnosis is usually suspected by the age of 3-6 months; the severely affected patients die usually before the third year of life.

\section{CLINICAL UTILITY}

3.1 (Differential) diagnosis: the tested person is clinically affected (To be answered if in 1.10 'A' was marked)

\subsubsection{Can a diagnosis be made other than through a genetic test?}

\begin{tabular}{ll}
\hline No & $\square$ (continue with 3.1.4) \\
Yes & $\square$ \\
& Clinically \\
Imaging & $\square$ \\
Endoscopy & $\square$ \\
Biochemistry & $\square$ \\
Electrophysiology & $\square$ \\
Other (please describe) & $\square$ \\
\hline
\end{tabular}

Biochemical investigations include copper accumulation test in cultured fibroblasts or measurement of plasma catecholamine levels (see section 1.6). There are several other investigations such as hair microscopy or brain MRI that may demonstrate different abnormalities characteristic for MD.

\subsubsection{Describe the burden of alternative diagnostic methods to the} patient.

Plasma catecholamine levels are distinctively abnormal in patients with MD and are being used in diagnosis in a few centres. ${ }^{10}$ This test is 
not a burden for the patient, but it does not provide definitive evidence for MD.

Copper accumulation test in cultured fibroblasts is a method that requires expertise and is also carried out in a few centres. ${ }^{10}$ This test requires a skin biopsy from the patient and may be a burden.

3.1.3 How is the cost effectiveness of alternative diagnostic methods to be judged?

As genetic test is the ultimate diagnosis, it should always be carried out when possible.

3.1.4 Will disease management be influenced by the result of a genetic test?

No $\square$

Yes $\otimes$

Therapy (please

describe)

If an MD patient can be diagnosed within the first weeks of life, parenteral administration of copper can be initiated. ${ }^{12}$ Early initiation of treatment may have a beneficial effect on neurodevelopment, but does not remove all the symptoms. It has to be kept in mind that the long-term benefits of copper treatment have only been documented in very few patients. Response to copper treatment is also likely to be dependent on the type of the underlying ATP7A mutation, and the patients retaining partial activity of the ATP7A protein are likely to have a better clinical prognosis with copper treatment. Therefore, although promising, copper replacement has been applied only to few cases and this treatment cannot be accepted as a definitive cure for MD, despite some reported successful outcomes.

Prognosis (please Copper-histidine treatment starting within the first describe) weeks of life has been shown to have a beneficial effect on neurodevelopment in some patients. ${ }^{12}$ Hence early diagnosis leads to early treatment and a better prognosis.

Management There is no definitive cure for MD and management is (please describe) mainly symptomatic.

3.2 Predictive setting: the tested person is clinically unaffected but carries an increased risk based on family history

(To be answered if in 1.10 ' $\mathrm{B}$ ' was marked)

3.2.1 Will the result of a genetic test influence lifestyle and prevention? If the test result is positive (please describe).

Not applicable.

If the test result is negative (please describe).

Not applicable.

3.2.2 Which options in view of lifestyle and prevention does a person at-risk have if no genetic test has been done (please describe)? Not applicable.

3.3 Genetic risk assessment in family members of a diseased person (To be answered if in 1.10 ' $\mathrm{C}$ ' was marked)

3.3.1 Does the result of a genetic test resolve the genetic situation in that family?

Yes. Once a given family's mutation has been characterised in a male with $\mathrm{MD}$, this will enable investigation of other family members.

3.3.2 Can a genetic test in the index patient save genetic or other tests in family members?

No. Each person who is suspected for MD should be tested.
3.3.3 Does a positive genetic test result in the index patient enable a predictive test in a family member?

Yes. Carrier diagnosis of females will be possible.

3.4 Prenatal diagnosis

(To be answered if in 1.10 'D' was marked)

3.4.1 Does a positive genetic test result in the index patient enable a prenatal diagnosis?

Yes. When the mutation of the family is known, it can be used in prenatal diagnosis through investigation of the given mutation directly in DNA isolated from chorion villus samples or amniotic fluid. If the mutation of the family/the mother is not known before pregnancy it may not be possible to carry out a prenatal genetic test, as the ATP7A gene is very large and almost each family has a different mutation.

In at-risk pregnancies in which the mutation of the family is unknown, biochemical analysis remains a possibility, as identification of the genetic defect may be challenging in limited time. In the first trimester, the total copper content in chorionic villi can be measured directly by sensitive and accurate methods such as neutron activation analysis and atomic absorption, and in the second trimester, copper accumulation is measured in cultured amniotic fluid cells. Although there are potential pitfalls for these analyses, they have been performed routinely at the Kennedy Center in Denmark since $1975 .^{9}$

\section{IF APPLICABLE, FURTHER CONSEQUENCES OF TESTING}

Please assume that the result of a genetic test has no immediate medical consequences. Is there any evidence that a genetic test is nevertheless useful for the patient or his/her relatives? (Please describe)

It is very important to identify the genetic defect in a Menkes patient. Once a given family's mutation has been characterised in a male index patient with MD, this will aid greatly in carrier detection of the mother and other female relatives. This is very important for future pregnancies and prenatal genetic testing. As the ATP7A gene is very large and almost each family has its distinct mutation, it may not be possible to carry out a prenatal test in due time if the mutation of the family is not known before pregnancy. Identification of the genetic defect in a given family is also of great importance for the female members of the family (such as sisters of the affected individuals) to know that they are not carriers. However, in such cases, germ-line mosaicism should always be kept in mind, as germ-line mosaicism has previously been shown for MD. ${ }^{13}$

\section{CONFLICT OF INTEREST}

The authors declare no conflict of interest.

\section{ACKNOWLEDGEMENTS}

This work was supported by EuroGentest, an EU-FP6 supported NoE, contract no. 512148 (EuroGentest Unit 3: 'Clinical genetics, community genetics and public health', Workpackage 3.2).

1 Tümer Z, Møller LB, Horn N: Mutation spectrum of ATP7A, the gene defective in Menkes disease. Adv Exp Med Biol 1999; 448: 83-95.

2 Tümer Z, Lund CL, Vural B, Tolshave J, Tønnesen T, Horn N: Identification of point mutations in 41 unrelated Menkes disease patients. Am J Hum Genet 1997; 60: 63-71.

$3 \mathrm{Gu} \mathrm{YH}$, Kodama H, Murata Y et al: ATP7A gene mutations in 16 patients with Menkes disease and a patient with occipital horn syndrome. Am J Med Genet 2001; 99: 217-222. 
4 Møller LB, Bukrinsky JT, Mølgaard A et al: Identification and analysis of 21 novel disease-causing amino acid substitutions in the conserved part of ATP7A. Hum Mutat 2005; 26: 84-93.

5 Human Gene Mutation Database, HGMD. (http://www.hgmd.org)

6 Tümer Z, Møller LB, Horn N: Screening of 383 unrelated patients with Menkes disease and finding of 57 gross deletions in ATP7A. Hum Mutat 2003; 22: 457-463.

7 Tümer Z, Tommerup N, Tønnesen T, Kreuder J, Craig IW, Horn N: Mapping of the Menkes locus to Xq13.3 distal to the X-inactivation center by an intrachromosomal insertion of the segment Xq13.3-q21.2. Hum Genet 1992; 88: 668-672.

8 Sirleto $\mathrm{P}$, Surace $\mathrm{C}$, Santos $\mathrm{H}$ et al: Lyonization effects of the $\mathrm{t}(\mathrm{X} ; 16)$ translocation on the phenotypic expression in a rare female with Menkes disease. Pediatr Res 2009; 65: 347-351.
9 Moizard M-P, Ronce N, Blesson S et al: Twenty-five novel mutations including duplications in the ATP7A gene. Clin Genet 2010; E-pub ahead of print 7 May 2010.

10 Tümer Z, Moller LB: Menkes disease. Eur J Hum Genet 2010; 18: 511-518.

11 Kennerson ML, Nicholson GA, Kaler SG et al: Missense mutations in the copper transporter gene ATP7A cause X-linked distal hereditary motor neuropathy. Am J Hum Genet 2010; 86: 342-352.

12 Christodoulou J, Danks DM, Sarkar B et al: Early treatment of Menkes disease with parenteral copper-histidine: long-term follow-up of four treated patients. Am J Med Genet 1998; 76: 154-164.

13 Poulsen L, Møller LB, Plunkett K, Belmont J, Tümer Z, Horn N: X-linked Menkes disease: first documented report of germ-line mosaicism. Genet Test 2004; 8: 286-291. 